\title{
Editorial.
}

\section{THE END-RESULTS OF THE TREATMENT OF "SHELL-SHOCK."}

HE outbreak of the great war found the countryperhaps all countries-unprepared for the new conditions which must inevitably arise. In some cases the unpreparedness may have been due to a lack of foresight, in other cases the problems could scarcely have been foreseen. Very early in the war it was obvious that a new and pressing problem had arisen - the problem of the " nerve sick " soldier. This problem has no doubt been presented to all ages and to all civilisations, but it is doubtful whether its seriousness could have been forecasted. At the outbreak of war none knew what would be the effect of modern methods of fighting, of higho explosives, or the prolonged state of what in effect were siege conditions. In any case, shortly after the Mons retreat theo seriousness of the problem was realised and steps were taken to meet it.

It is now more than twelve years since the first hospitals for cases of "shell-shock" were opened in this country. At the hands of various men various forms of treatment were used in these hospitals, in some cases a hospital employing almost exclusively a particular line of treatment, in other cases more broad-minded policies being adopted. These institutions were increased in numbers as the war proceeded, and in many cases were continued long after the cessation of hostilities.

Twelve years' experience must have provided a mass of information which might be of the greatest value. All who are connected with this speciality of medical science know that in individual cases each line of treatment was successful. General information is, however, urgently needed as to the mass effects of the different lines of treatment and the suitability of each to the different kinds of individual. Does isolation, hypnotism, Freudism, or any other particular form of treatment give the best results in the mass? If all of these lines of treatment are uniformly successful (as they are not), which is the most 
rapid in effecting its cure ? If none of them is uniformly successful, to what types of individuals is each the best adapted?

The literature of this subject bears evidence of careful and painstaking examination of the effects of specific forms of treatment, but there is little evidence obtainable as to the comparative success of the divergent modes.

In the early days of the war the exponents of one or other form of treatment not uncommonly took the position that the particular treatment was founded upon the most rational theoretical basis, but that its practical results could alone be measured after a lapse of years. There was no doubt at that time some divergence between individual estimates of value regarding the theoretical foundations of different lines of treatment, but Time has now played his card.

There are available to-day great sources of information with regard to the later effects of the treatment of "shellshock." The entry books of the special hospitals, the medical history sheets of the patients, and their subsequent histories in the possession of the Ministry of Pensions, together no doubt with other sources of information, combine to give data the marshalling of which, in Baedeker's words, would be "laborious but repaying." A statistical examination of the histories of the cases admitted to certain of the "shell-shock" hospitals which notoriously specialised their lines of treatment would give evidence with regard to the mass effect of the specific form of treatment. In the early years of the war the necessary absence of any data with regard to the ultimate effects of different forms of treatment naturally led to some overestimates. A cooler and more judicial examination of the practical effects now available (should the data be sought) might yield knowledge which would be of the greatest practical importance not only in these present days of peace, but if-which God forbid-we should again be faced with the problems of August 1914. 